\title{
Microleakage in combined amalgam/composite resin restorations in MOD cavities
}

\author{
Kosmas Tolidis ${ }^{1}$, Christina Boutsiouki ${ }^{1}$, Paris Gerasimou ${ }^{1}$ \\ 'Department of Operative Dentistry, School of Dentistry, Aristotle University of Thessaloniki, Greece
}

\begin{abstract}
Aim: To compare marginal seal at tooth-material and material-material interfaces in the proximal box in combined amalgam/composite resin restorations. Methods: Mesio-occlusal-distal (MOD) cavities were prepared in 35 premolars and permanent molars with carbide bur. The distal proximal box was restored with amalgam (Permite, SDI) until reaching the height of pulpal floor. Dental tissues were etched with 37\% acid and a bonding agent (Bond 1-SF, Pentron) was applied and cured. Composite resin (Filtek Z250, 3M-ESPE) was placed in layers in the mesial proximal box and occlusally, and light cured. Marginal adaptation was evaluated at the following interfaces: amalgam-tooth (A), amalgam-composite resin (AC) and composite resin-tooth (C). Microleakage was evaluated by means of methylene blue infiltration after 7-day water storage and thermocycling regimen (1500 cycles). Microleakage was assessed as percentage depth of horizontal dye penetration. Results: ANOVA showed statistically significant difference between $A-A C$ and $A-C(p<0.01)$. No statistically significant difference was found between AC-C interfaces (p>0.05). Mean microleakage values were A (73.529/28.71), AC (34.118/34.6) and C (40.435/ 34.965), according to Tukey's test. Conclusions: Although the bonding mechanism between amalgam and composite has not yet been completely explained, amalgam/composite resin interface exhibited the lowest microleakage scores. Since amalgam/composite resin restorations exhibited lower microleakage scores than composite resin on the cervical surface, combined restorations can be considered as a biological and aesthetic alternative to conventional Class II composite or amalgam restorations.
\end{abstract}

Keywords: combined restorations, amalgam-composite, microleakage, class II cavity, MOD cavity.

\section{Introduction}

Secondary caries is still cause for composite resin restoration failure ${ }^{1}$. Teeth restored using composite resins are especially prone to this phenomenon due to stress generated within the tooth-restoration interface following resin contraction during polymerization, known as polymerization shrinkage ${ }^{2}$. Should the

Received for publication: February 09, 2013 Accepted: May 22, 2013

Correspondence to: Christina Boutsiouki 12 Kallidopoulou Str. 54642, Thessaloniki, Greece Phone: +306945822764

Fax: +302310863631

E-mail: christinaboutsiouki@gmail.com accumulated polymerization contraction stress result in tooth-composite adhesive failure ${ }^{3-4}$, bacterial aggregation at the disrupted tooth-restoration margin may occur resulting in microleakage and later secondary caries. Furthermore, bonding on the cervical surface of Class II composite restorations is complex. Despite the favorable presence of cervical enamel, composite resin bonding on cervical surface of proximal box usually takes place on aprismatic enamel or dentine. Bonding onto aprismatic enamel is compromised by altered etching pattern ${ }^{5}$ and dentin bond is degraded, especially in permanent teeth ${ }^{5-6}$. Lower level of dentin 
mineralization, challenging moisture control for application of adhesive system, presence of tubular fluid and bonddegrading matrix-metalloproteinases hinder bonding to dentin $^{5}$, making composite placement a technique-sensitive procedure ${ }^{7}$. Thereby, both polymerization shrinkage and quality of the bond seem to be responsible for the degradation of marginal adaptation. Microleakage is strongly controlled by marginal adaptation and is thought to be one of the major disadvantages of resin composite restorations ${ }^{8}$. Although composite resins exhibit better initial marginal adaptation than amalgam $^{9}$, amalgam restorations rarely fail due to secondary caries ${ }^{10}$. Amalgam surface corrosion and deposition of oxides improve marginal auto-sealing over time ${ }^{11}$. In contrast to composite resins, amalgam is dimensionally stable.

The aim of the present study was to compare marginal seal in tooth-material and material-material interfaces in the proximal box in combined amalgam/composite resin restorations via microleakage. The null hypothesis was that there is no difference in microleakage values between any of the tested interfaces.

\section{Material and methods}

A group of 35 freshly extracted maxillary and mandibular premolars and permanent molars was collected from a private dental office. Authorization was obtained from the owner of the dental office and only teeth extracted for orthodontic and periodontal reasons or impacted third molars were included in the study, for ethical reasons.

Teeth free of caries and fractures were stored in saline and not allowed to dry throughout the whole experiment. Standard mesio-occlusal-distal (MOD) cavities were prepared with carbide burs at high speed under air-water spray (depth of $1 \mathrm{~mm}$ beneath dentinoenamel junction, buccolingual width of $2.5 \mathrm{~mm}$, mesiodistal width of cervical surface of proximal box of $2 \mathrm{~mm}$ ). All margins were placed on enamel and proximal boxes were extended until $1 \mathrm{~mm}$ above cervix (Figure 1). Bur was discarded after each preparation. Teeth were solely mounted with no contact points. A $7 \mathrm{~mm}$-wide metallic matrix was used. Distal proximal box was restored with amalgam (Permite; SDI Limited, Bayswater, Australia) until reaching the height of pulpal floor.

Each increment was condensed with maximum hand pressure, using the appropriate condenser size. Surface mercury-rich amalgam layer was removed after condensation. After 5 minutes, dental tissues and amalgam surface were etched with $37 \%$ phosphoric acid (Ultra-Etch; Ultradent Products Inc., South Jordan, UT, USA) and bonding agent (Bond 1-SF; Pentron Clinical Technologies, Los Angeles CA, USA) was applied on both and cured for $10 \mathrm{~s}$ according to the manufacturer's instructions. No additional preparation was performed for the amalgam surface. Composite resin (Filtek Z250; 3M-ESPE GmbH, Neuss, Germany) was inserted in layers in mesial proximal box and was cured for $20 \mathrm{~s}$ each layer. Subsequently, the occlusal surface was restored with the same composite, covering both proximal boxes. Marginal adaptation was evaluated at the following interfaces:

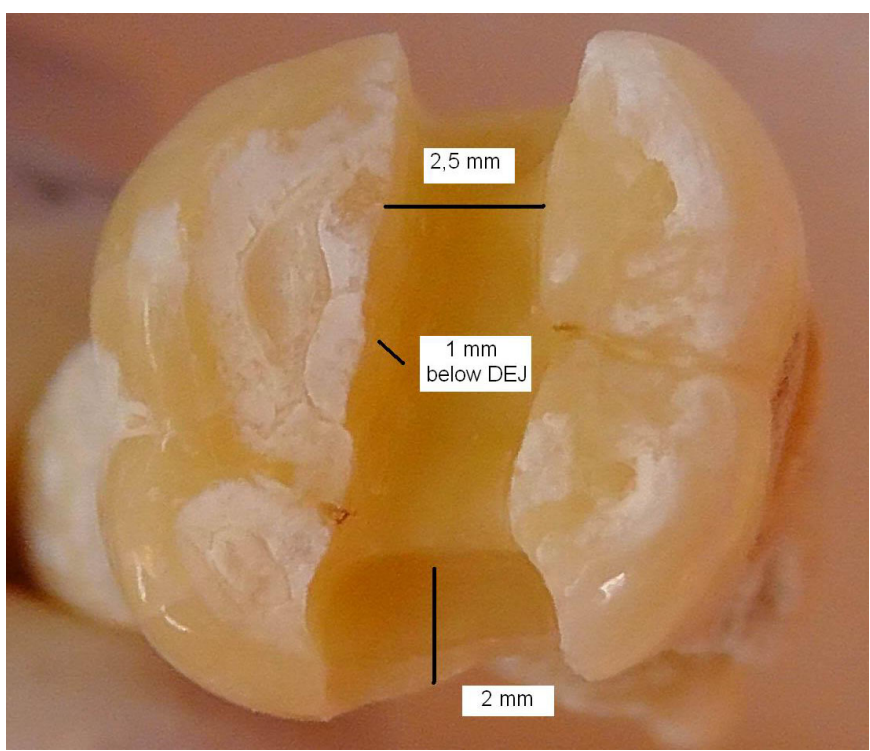

Fig. 1. Preparation of MOD cavity and its dimensions

amalgam-tooth (A), amalgam-composite resin (AC), composite resin-tooth $(\mathrm{C})$.

Teeth were kept in saline at room temperature $\left(20^{\circ} \mathrm{C}\right)$ for 1 week. All teeth were thermocycled for 1,500 cycles at $5^{\circ} \mathrm{C}-36^{\circ} \mathrm{C}-55^{\circ} \mathrm{C}-36^{\circ} \mathrm{C}$ with a dwell time of $15 \mathrm{~s}$. These temperatures were chosen in an effort to reproduce thermal changes in the intraoral environment. Teeth were then covered with nail varnish except for the restoration area and $1 \mathrm{~mm}$ around it, in order to avoid false positive results via dye penetration from another point rather than the restoration margins. Following that, the teeth were immersed in 5\% aqueous solution of methylene blue for $24 \mathrm{~h}$. After that they were washed with saline and cut longitudinally by a microtome (Figure 2). In order to assess the degree of microleakage at the occlusal margin, photographs were taken for each cut, under a stereomicroscope at 100x magnification.

Two specimens were excluded from the survey due to

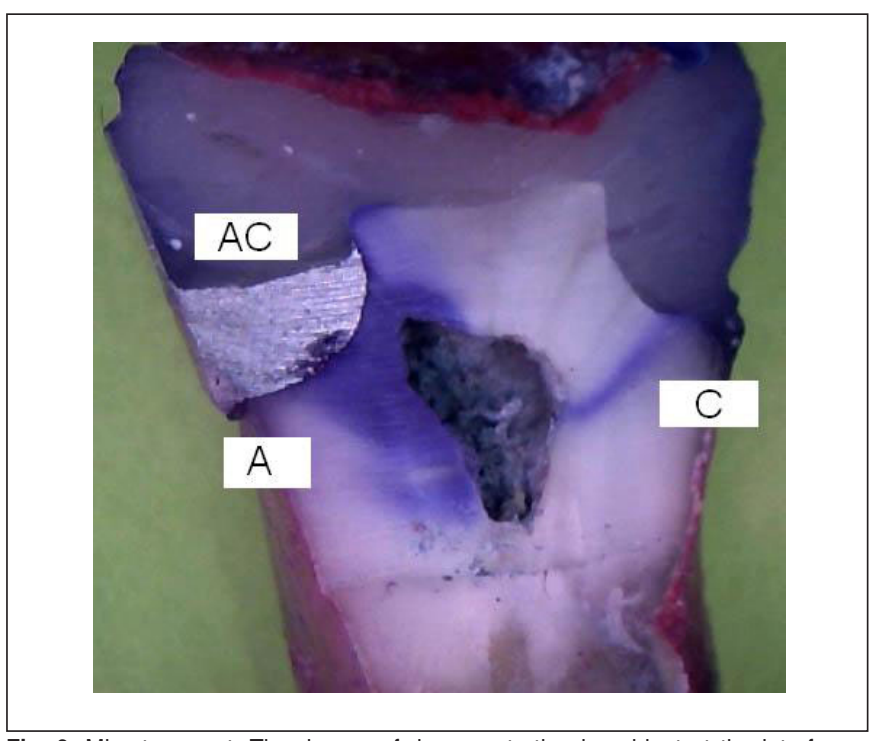

Fig. 2. Microtome cut. The degree of dye penetration is evident at the interfaces: amalgam-tooth $(A)$, amalgam-composite resin $(A C)$ and composite resin-tooth $(C)$. 
additional dye penetration through minor fractures. Microleakage was assessed as percentage depth of horizontal penetration (infiltration extent/cavity extension) (Table 1). Descriptive statistics including means and standard deviations were calculated for the microleakage analysis. The obtained data were subjected to one-way analysis of variance (ANOVA) and Tukey-Kramer multiple-comparison test to determine significant differences among the three interfaces. The level of significance was set at $p=0.05$. All statistical analyses were performed using SPSS 12.0 (SPSS Inc., Chicago, IL, USA).

\section{Results}

Mean microleakage values, from higher to lower, were as follows: A (73.529/28.71), C (40.435/34.965) and AC
(34.118/34.6). Statistically significant difference was observed between A-AC and A-C $(\mathrm{p}<0.01)$, but no statistically significant difference could be found between $\mathrm{AC}-\mathrm{C}$ interfaces $(p>0.05)$.

\section{Discussion}

The first combined amalgam/composite case report was published in 1982 and presented a mandibular premolar, which was restored occlusally with composite resin in order to mask the unaesthetic amalgam ${ }^{12}$. Combined amalgam/ composite restorations have been investigated in the recent literature in terms of bonding strength ${ }^{13}$ or are suggested as an alternative for amalgam repair without sacrificing healthy tissues $^{14}$ or as a means for increasing cusp fracture resistance ${ }^{14}$. There are few studies on marginal seal ${ }^{14-18}$ and fewer still do

Table 1 - Microleakage exhibited as percentage \% depth of horizontal penetration (infiltration extent / cavity extension) in the interfaces examined.

\begin{tabular}{|c|c|c|c|}
\hline No. & $\begin{array}{l}\text { AMALGAM - TOOTH } \\
\text { (A) }\end{array}$ & $\begin{array}{c}\text { AMALGAM - COMPOSITE } \\
\text { (AC) }\end{array}$ & $\begin{array}{c}\text { COMPOSITE - TOOTH } \\
\text { (C) }\end{array}$ \\
\hline 1 & 100 & 80 & 100 \\
\hline 2 & 70 & 50 & 0 \\
\hline 3 & 70 & 30 & 40 \\
\hline 4 & 100 & 0 & 100 \\
\hline 5 & 100 & 10 & 20 \\
\hline 6 & 70 & 40 & 40 \\
\hline 7 & 50 & 40 & 0 \\
\hline 8 & 30 & 10 & 100 \\
\hline 9 & 70 & 30 & 40 \\
\hline 10 & 100 & 100 & 50 \\
\hline 11 & 70 & 30 & 40 \\
\hline 12 & 100 & 0 & 20 \\
\hline 13 & 80 & 70 & 0 \\
\hline 14 & 50 & 0 & 0 \\
\hline 15 & 20 & 0 & 50 \\
\hline 16 & Excluded & Excluded & Excluded \\
\hline 17 & 70 & 30 & 40 \\
\hline 18 & 50 & 20 & 0 \\
\hline 19 & 100 & 30 & 80 \\
\hline 20 & 70 & 30 & 30 \\
\hline 21 & 50 & 20 & 60 \\
\hline 22 & 70 & 30 & 40 \\
\hline 23 & Excluded & Excluded & Excluded \\
\hline 24 & 70 & 30 & 40 \\
\hline 25 & 100 & 100 & 30 \\
\hline 26 & 70 & 30 & 40 \\
\hline 27 & 60 & 30 & 30 \\
\hline 28 & 50 & 10 & 0 \\
\hline 29 & 60 & 30 & 40 \\
\hline 30 & 100 & 40 & 20 \\
\hline 31 & 70 & 30 & 40 \\
\hline 32 & 70 & 30 & 40 \\
\hline 33 & 70 & 30 & 40 \\
\hline 34 & 50 & 20 & 40 \\
\hline 35 & 70 & 30 & 50 \\
\hline
\end{tabular}


investigate microleakage at the amalgam/composite resin interface ${ }^{14,17-18}$. Franchi et al. (1994) ${ }^{17}$ and Franchi et al. $(1999)^{15}$ demonstrated that microleakage at the amalgam/ composite resin interface was in between amalgam/enamel (higher) and composite resin/enamel (lower), results which partially match our findings.

The present study showed that microleakage at the materials' interface was lower than microleakage around amalgam or composite. However, contrary to the used methodology, specimens in those studies were not thermocycled, assuming that thermal loading may have an effect on microleakage at amalgam/composite interface and may explain the opposite findings.

In contrast, Cehreli et al. $(2010)^{14}$ demonstrated that microleakage at the amalgam/composite resin interface was higher than at the tooth interface, but dealt with old amalgam as a substrate. It seems that use of fresh amalgam is favorable in terms of sealing ability at the interface of an amalgam/ composite combined restoration. A similar study has been performed with primary molars, reaching the same results for amalgam/composite interface as in the conducted study ${ }^{19}$. Kournetas et al. $(2010)^{18}$ used a qualitative scale and concluded that marginal adaptation in amalgam/composite resin interface is comparable to composite/tooth with self-etch adhesive. Type of materials tested, cavity preparation, type of dental tissue, tooth age, amalgam condensation, amalgam surface conditioning, amalgam and composite bonding procedures, composite placement and polymeri-zation, use of oxidation solution for amalgam, thermocycling and type of used dye, all affect microleakage values and impose limitations for direct comparisons between the published papers. Moreover, in vitro microleakage does not necessarily predict in vivo restoration failure due to secondary caries. Even though a threshold marginal gap size for clinical failure of the restorations has not been established ${ }^{20}$, restorations with marginal defects fail more frequently ${ }^{21}$. In spite of these limiting aspects, microleakage was chosen in this study because of its longterm report in the literature.

Concerning the present study, since teeth had no contact points, a matrix system was used in order to condense amalgam into the proximal box. Despite the fact that fresh amalgam has high surface tension ${ }^{22}$, which affects negatively the wettability of the surface, composite resin was inserted after only $5 \mathrm{~min}$ in order to mimic clinical conditions. This approach seems to be time saving and the use of a temporary restoration over the placed amalgam is avoided. Composite was applied in layers in order to control polymerization shrinkage. Since high-copper amalgam was placed, no oxidation solution was used, in order to comply with previous studies. Higher microleakage values at the amalgam/tooth interface, which are not confirmed by clinical experience ${ }^{10}$, could be attributed to condensation technique and lack of oxidation solution. In contrast, ideal presence of cervical enamel for bonding and placement of the material in layers, seem to be the reasons for lower microleakage at the composite resin/tooth interface.

The use of amalgam in the cervical surface of proximal boxes has been related to a good marginal seal ${ }^{23}$. Adding the advantageous time-dependent auto-sealing due to gradual oxide deposition ${ }^{11}$, amalgam is regarded as the material of choice regarding optimum marginal behavior. This study showed that the amalgam/composite resin interface performs even better, concluding that despite the use of two completely different materials, there is an excellent marginal seal. Since the bonding mechanism is not fully understood ${ }^{24}$, questions arise regarding the irregularities of the amalgam surface, the higher surface tension of fresh amalgam, the entrapment of air, the presence of a "hybrid" surface or the proliferation of the setting reaction, which could possibly affect marginal integrity. However, even mechanical loading does not affect marginal adaptation of the interface ${ }^{18}$, eliminating the issue of a possible failure of the interface due to occlusal forces. A recent in vivo study on one-hundred posterior teeth, demonstrated that combined restorations performed better for contact, contour and retention than conventional composite resin or amalgam restorations ${ }^{25}$.

Combined amalgam/composite restorations are not thoroughly researched, as shown by the aforementioned drawbacks, but in vitro microleakage results are convincing. Lacking alternative conservative aesthetic restorative options, which would improve the quality of the cervical area of Class II restorations, and considering the research limitations, combined amalgam/composite resin restorations can be suggested. Combined restorations should be employed in challenging clinical situations, particularly in cases of proximal boxes with cervical margins located near the gingiva or beneath the cementoenamel junction. Controlled clinical trials involving the implementation of this technique should be performed to determine its usefulness, durability and longevity.

The conclusion is that despite the fact that amalgam and composite are two completely different materials their interface exhibited the lowest microleakage values. Within the limitations of an in vitro study, they can be combined in Class II restorations.

\section{References}

1. Turkun LS, Aktener $\mathrm{O}$, Ates M. Clinical evaluation of different posterior resin composite materials: a 7-year report. Quintessence Int. 2003; 34: 418-26.

2. Gomes GM, Bittencourt BF, Pilatti GL, Gomes GC, Gomes OMM, Calixto AL. Effect of light-curing units on gap formation and microleakage of class II composite restorations. Braz J Oral Sci. 2011; 10: 262-7.

3. Oliveira KM, Consani S, Gonçalves LS, Brandt WC, Ccahuana-Vásquez RA. Photoelastic evaluation of the effect of composite formulation on polymerization shrinkage stress. Braz Oral Res. 2012; 6: 202-8.

4. Ishikiriama SK, Valeretto TM, Franco EB, Mondelli RFL. The influence of "C-factor" and light activation technique on polymerization contraction forces of resin composite. J Appl Oral Sci. 2012; 20: 603-6.

5. Pashley DH, Tay FR, Breschi L, Tjaderhane L, Carvalho RM, Carrilho $M$, et al. State of the art etch-and-rinse adhesives. Dent Mater. 2011; 27: 11-6.

6. Lenzi TL, Soares FZ, Rocha R O. Degradation of resin-dentin bonds of etch-and-rinse adhesive system to primary and permanent teeth. Braz Oral Res. 2012; 26: 511-5. 
7. ADA Council on Scientific Affairs, ADA Council on Dental Benefit Programs. Statement on posterior resin-based composites. J Am Dent Assoc. 1998; 129: 1627-8.

8. Davidson $\mathrm{CL}$, de Gee AJ, Feilzer A. The competition between the composite-dentin bond strength and the polymerization contraction stress. J Dent Res. 1984; 63: 1396-9.

9. Duncalf WV, Wilson NH. Marginal adaptation of amalgam and resin composite restorations in Class II conservative preparations. Quintessence Int. 2001; 32(5): 391-5.

10. Bernardo M, Luis $\mathrm{H}$, Marin MD, Leroux BG, Rue T, Leitao $\mathrm{J}$ et al. Survival and reasons for failure of amalgam versus composite posterior restorations placed in a randomized clinical trial. J Am Dent Asssoc. 2007; 138: 775-83.

11. Johansson BI, Mjor IA. Marginal degradation and corrosion of a dispersed high copper amalgam. Scand J Dent Res. 1988; 96: 75-82.

12. Anglis LF, Fine $L$. The amalgam-composite resin restoration. J Prosth Dent. 1982; 47:685.

13. Blum IR, Hafiana K, Curtis A, Barbour ME, Attin T, Lynch CD, et al. The effect of surface conditioning on the bond strength of resin composite to amalgam. J Dent. 2012; 40: 15-21.

14. Cehreli SB, Arhun N, Celik C. Amalgam repair: quantitative evaluation of amalgam-resin and resin-tooth interfaces with different surface treatments. Oper Dent. 2010; 35: 337-44.

15. Franchi M, Breschi L, Ruggeri O. Cusp fracture resistance in compositeamalgam combined restorations. J Dent. 1999; 27: 47-52.

16. Rodrigues Junior SA, Pin LFS, Machado G, Della Bona A, Demarco FF. Influence of different restorative techniques on marginal seal of class II composite restorations. J Appl Oral Sci. 2010; 18: 37-43.

17. Franchi M, Trisi P, Montamari G, Piattelli A. Composite resin-amalgam compound restorations. Quintessence Int. 1994; 25: 577-82.

18. Kournetas N, Kakaboura A, Giftopoulos D, Chakmachi M, Rahiotis C, Geis-Gerstofer J. Marginal behaviour of self-etch adhesive/composite and combined amalgam-composite restorations. Europ J Prosthodont Restor Dent. 2010; 18: 70-7.

19. Hovav S, Holan G, Lewinstein I, Fuks AB. Microleakage of class 2 Superbond-lined composite restorations with and without a cervical amalgam base. Oper Dent. 1995; 20: 63-7.

20. Jokstad A, Bayne S, Blunck U, Tyas M, Wilson N. Quality of dental restorations. FDI Commission Project 2-95. Int Dent J. 2001; 51: 117-58.

21. Hayashi M, Wilson NH. Marginal deterioration as a predictor of failure of a posterior composite. Eur J Oral Sci. 2003; 111: 155-62.

22. Morge $\mathrm{S}$, Adamczak $\mathrm{E}$, Linden LA. Variation in human salivary pellicle formation on biomaterials during the day. Arch Oral Biol. 1989; 34: 669-74.

23. Demarco FF, Ramos OL, Mota CS, Formolo E, Justino LM. Influence of different restorative techniques on microleakage in class II cavities with gingival wall in cementum. Oper Dent. 2001; 26: 253-9.

24. Ozcan M, Vallittu PK, Huysmans MC, Kalk W, Vahlberg T. Bond strength of resin composite to differently conditioned amalgam. J Mater Sci Mater Med. 2006; 17: 7-13.

25. Kaur G, Singh M, Bal C, Singh U. Comparative evaluation of combined amalgam and composite resin restorations in extensively carious vital posterior teeth: An in vivo study. J Conserv Dent. 2011; 14: 46-51. 